\title{
Serum vitamin D status in children and adolescence with diabetes according to season and age
}

\author{
Sung Su Jung, MD, \\ Min Sun Kim, MD, \\ Dae Yeol Lee, MD \\ Department of Pediatrics, \\ Chonbuk National University \\ Medical School, Jeonju, Korea
}

Received: 11 September, 2013 Revised: 14 November, 2013 Accepted: 10 December, 2013

Address for correspondence: Dae Yeol Lee, MD

Department of Pediatrics, Chonbuk National University Hospital, Chonbuk National University Medical School, 20 Geonji-ro, Deokjin-gu, Jeonju 561-712, Korea

Tel: +82-63-250-1460

Fax: +82-63-250-1464

E-mail: leedy@chonbuk.ac.kr
Purpose: It is known that children with diabetes have more severe vitamin $D$ deficiency than healthy children. This study aimed to investigate serum vitamin $D$ status and analyze the relationships between serum vitamin $D$ levels and clinical parameters in children with diabetes.

Methods: We checked serum vitamin D levels of children with diabetes aged below 18 years who were treated at our Department of Pediatrics between December 2011 and February 2012 (winter) as well as between June 2012 and August 2012 (summer). We retrospectively analyzed relationships between their serum vitamin $D$ levels and clinical parameters.

Results: The serum 25-hydroxyvitamin $\mathrm{D}$ level in children with diabetes during winter was markedly lower than during summer $(10.8 \pm 5.1 \mathrm{ng} / \mathrm{mL}$ vs. $17.6 \pm 5.6$ $\mathrm{ng} / \mathrm{mL}$ ); vitamin D deficiency was more prevalent during winter (95\% vs. $62 \%$ ). However, there was no difference between children with diabetes and healthy children. In children with type I diabetes mellitus, among all the clinical parameters, age had the greatest negative correlation with serum vitamin $D$ level.

Conclusion: In children with diabetes, serum vitamin D levels showed marked seasonal variation. However, no clear relationship was identified between vitamin $\mathrm{D}$ deficiency and diabetes. This was because the control group had an equally high vitamin $D$ deficiency rate. Additional studies including other clinical parameters after vitamin $D$ supplementation in children with diabetes should be considered.

Keywords: Vitamin D, Diabetes mellitus, Seasons, Age, Child

\section{Introduction}

Vitamin D is known to affect calcium metabolism, bone growth, and (along with parathyroid hormone) maintenance of mineral homeostasis. Recently, the vitamin D receptor has been discovered in various tissues in the body; it is necessary to convert 1 alpha-hydroxylase (1-hydroxylase) into the active form of vitamin D. Therefore, the functions of vitamin D have been described through a new perspective ${ }^{1)}$. The most common cause of vitamin $\mathrm{D}$ deficiency is inadequate sun exposure. Vitamin D deficiency causes not only skeletal disease such as rickets and osteomalacia but also nonskeletal diseases such as malignancies and cardiovascular and autoimmune diseases ${ }^{2,3)}$.

Pittas et al. ${ }^{4)}$ and Zipitis and Akobeng ${ }^{5)}$ reported that vitamin D supplementation affected the development of type 1 and 2 diabetes mellitus (DM). Therefore, this study aimed to investigate the variations in serum vitamin $\mathrm{D}$ levels in children and adolescents with diabetes according to season and age in comparison to those in healthy children and to analyze the relationships between serum vitamin $\mathrm{D}$ level and clinical parameters in children with diabetes. 


\section{Materials and methods}

\section{Subjects}

We evaluated the serum vitamin D levels of children with diabetes who were younger than 18 years and treated at the Department of Pediatrics, Chonbuk National University Hospital, between December 2011 and February 2012 (winter) and June 2012 and August 2012 (summer). We retrospectively compared children with diabetes and healthy children in terms of vitamin D serum level and deficiency rate, and analyzed the relationships between serum vitamin D level and clinical parameters (age, body mass index [BMI], glucose, alkaline phosphatase [ALP], cholseterol, triglyceride, lipid profile, C-peptide, glycosylated hemoglobin [HbAlc], insulin dose) in children with diabetes. None of the study subjects received vitamin D supplementation during the study period.

The children with diabetes were further classified according to age as follows: the elementary school group (age, 7-12 years), the middle school group (age, 13-15 years), and the high school group (age, 16-18 years). Data obtained from all groups was compared and analyzed.

Table 1. Demographic findings and 25-OHD level of patients with diabetes and healthy control groups $(n=115)$

\begin{tabular}{lcccc}
\hline Variable & Type 1 DM & Type 2 DM & Total & Control \\
\hline Season & & & & \\
Winter & 51 & 15 & 66 & 49 \\
Summer & 51 & 20 & 71 & 87 \\
Age $(\mathrm{yr})$ & $13.3 \pm 4.2$ & $15.0 \pm 2.7$ & $13.8 \pm 3.9$ & $13.5 \pm 2.27$ \\
Male sex & $41 / 61(33.6)$ & $17 / 18(48.6)$ & $58 / 79(42.3)$ & $58 / 78(42.6)$ \\
BMl $\left(\mathrm{kg} / \mathrm{m}^{2}\right)$ & $19.2 \pm 3.9$ & $24.1 \pm 4.0$ & $20.4 \pm 4.4$ & $19.78 \pm 6.0$ \\
25-OHD $(\mathrm{ng} / \mathrm{mL})$ & $14.5 \pm 6.4$ & $13.8 \pm 5.3$ & $14.3 \pm 6.2$ & $16.1 \pm 6.2$ \\
\hline
\end{tabular}

Values are presented as mean \pm standard deviation or number (\%). 25-OHD, 25-hydroxy vitamin D; DM, diabetes mellitus; BMI, body mass index.

\section{Anthropometric and laboratory measurements}

Serum levels of 25-hydroxyvitamin D (25-OHD) were detected by performing chemiluminescence immunoassay; deficiency was defined as a level of vitamin $\mathrm{D}<20 \mathrm{ng} / \mathrm{mL}$.

\section{Statistical analysis}

All analyses were conducted by using the PASW ver. 18.0 (SPSS Inc., Chicago, IL, USA). All variables were expressed as the means \pm standard deviations. The independent two-sample $t$-tests and one-way analysis of variance were used to compare clinical parameters between groups. Relationships between serum vitamin D levels and clinical parameters were assessed by using Pearson correlation coefficient and second-order partial correlation, controlling for age and BMI. Statistical significance was defined as $P<0.05$ for all clinical and laboratory data.

\section{Results}

\section{General characteristics}

There were 66 (type 1, 51; type 2, 15) and 71 (type 1, 51; type $2,20)$ children with diabetes in summer and winter, respectively. The healthy control groups, matched according to age and sex, consisted of 49 and 87 children in winter and summer, respectively (Table 1). BMIs were markedly higher in children with type $2 \mathrm{DM}$ than in the control group or those with type 1 DM.

\section{Clinical characteristics of children with diabetes and vitamin $\mathrm{D}$ deficiency rate in winter}

The mean age of the children with diabetes was $14.5 \pm 4.3$ years and that of the control group children was $14.4 \pm 1.9$ years, which is similar. However, serum levels of cholesterol and low-density

Table 2. Clinical characteristics of patients with diabetes during winter $(n=115)$

\begin{tabular}{|c|c|c|c|c|c|}
\hline Characteristic & Type 1 DM & Type 2 DM & Total & Control & $P$-value $e^{\text {a) }}$ \\
\hline No. of patients & $51(77.3)$ & $15(22.7)$ & $66(100.0)$ & 49 & \\
\hline Age (yr) & $13.95 \pm 4.62$ & $16.47 \pm 2.02$ & $14.52 \pm 4.29$ & $14.48 \pm 1.96$ & 0.959 \\
\hline M/F (male\%) & $21 / 30(41.2)$ & $7 / 8(46.7)$ & 28/38 (42.4) & $21 / 28(42.8)$ & 0.963 \\
\hline BMI $\left(\mathrm{kg} / \mathrm{m}^{2}\right)$ & $19.36 \pm 3.94$ & $24.46 \pm 3.30$ & $20.52 \pm 4.35$ & $21.07 \pm 8.55$ & 0.657 \\
\hline Cholesterol (mg/dL) & $190.25 \pm 41.24$ & $196.53 \pm 54.82$ & $191.68 \pm 44.30$ & $154.95 \pm 29.14$ & $<0.001$ \\
\hline TG (mg/dL) & $139.45 \pm 114.95$ & $141.47 \pm 87.08$ & $139.91 \pm 108.61$ & $107.51 \pm 79.92$ & 0.096 \\
\hline LDL-cholesterol (mg/dL) & $103.60 \pm 33.62$ & $119.71 \pm 48.58$ & $107.13 \pm 37.57$ & $81.25 \pm 24.02$ & 0.025 \\
\hline $25-\mathrm{OHD}(\mathrm{ng} / \mathrm{mL})$ & $11.29 \pm 5.14$ & $9.19 \pm 1.79$ & $10.81 \pm 4.67$ & $10.98 \pm 3.97$ & 0.847 \\
\hline$<10$ & $24(47.1)$ & $11(73.3)$ & $35(53.0)$ & $21(43.9)$ & \\
\hline 10 to $<20$ & $23(45.1)$ & $4(26.7)$ & $27(40.9)$ & $27(55.1)$ & \\
\hline 20 to $<30$ & $3(5.9)$ & 0 & $3(4.5)$ & $1(2.0)$ & \\
\hline$\geq 30$ & $1(2.0)$ & 0 & $1(1.5)$ & 0 & \\
\hline
\end{tabular}

Values are presented as number (\%) or mean \pm standard deviation.

DM, diabetes mellitus; BMI, body mass index; TG, triacylglyceride; LDL; low-density lipoprotein; 25-OHD, 25-hydroxy vitamin D.

a)Total vs. control. 
lipoprotein (LDL) showed significant differences (Table 2).

In the children with diabetes, serum levels of 25-OHD were low $(10.8 \pm 4.7 \mathrm{ng} / \mathrm{mL})$ and the vitamin $\mathrm{D}$ deficiency rate was $94 \%$. The control group also showed low serum levels of $25-$ OHD $(11.0 \pm 4.0 \mathrm{ng} / \mathrm{mL})$ and high vitamin $\mathrm{D}$ deficiency rate (98\%), similar to the diabetes group. However, in children with diabetes, there were more patients with serum 25-OHD levels below $10 \mathrm{ng} / \mathrm{mL}$ than in the control group.

Among the 66 children with diabetes, children with type 2 DM were excluded because of insufficient numbers; the remaining 51 were compared and analyzed according to school grade and age. As shown in Table 3, there were remarkable differences in the duration of diabetes, BMIs, ALP levels, and lipid profiles, but no differences were seen in serum glucose and

Table 3. Clinical characteristics according to age in patients with type 1 DM during winter $(n=51)$

\begin{tabular}{|c|c|c|c|c|}
\hline \multirow{2}{*}{ Characteristic } & \multicolumn{3}{|c|}{ Grade } & \multirow{2}{*}{$P$-value } \\
\hline & Elementary school (7-12 yr) & Middle school (13-15 yr) & High school (16-18 yr) & \\
\hline No. of patients & $20(39.2)$ & $10(19.6)$ & $21(41.2)$ & \\
\hline Age (yr) & $8.95 \pm 2.17^{c)}$ & $14.44 \pm 1.05^{c}$ & $18.47 \pm 1.36^{c}$ & $<0.001^{\text {b) }}$ \\
\hline DM duration (yr) & $3.02 \pm 1.78$ & $4.55 \pm 2.36$ & $7.52 \pm 4.88^{c)}$ & $0.001^{b)}$ \\
\hline M/F (male\%) & $8 / 12(40.0)$ & $3 / 7(30.0)$ & 10/11(47.6) & 0.618 \\
\hline Body mass index $\left(\mathrm{kg} / \mathrm{m}^{2}\right)$ & $16.18 \pm 1.94^{c}$ & $20.23 \pm 2.50$ & $21.99 \pm 3.83$ & $<0.001^{b)}$ \\
\hline ALP (IU/L) & $322.50 \pm 81.12^{c)}$ & $203.40 \pm 121.39^{c)}$ & $118.24 \pm 32.67^{c}$ & $<0.001^{\text {b) }}$ \\
\hline Glucose (mg/dL) & $262.39 \pm 117.49$ & $212.90 \pm 130.32$ & $222.65 \pm 114.50$ & 0.475 \\
\hline HbA1c (\%) & $8.68 \pm 1.29$ & $9.65 \pm 1.49$ & $9.31 \pm 1.82$ & 0.225 \\
\hline C-peptide (ng/mL) & $0.50 \pm 1.00$ & $0.45 \pm 1.15$ & $0.40 \pm 0.80$ & 0.944 \\
\hline Cholesterol (mg/dL) & $173.85 \pm 30.45^{c}$ & $211.70 \pm 41.55^{c)}$ & $195.67 \pm 45.43$ & $0.041^{b)}$ \\
\hline Triacylglyceride (mg/dL) & $93.65 \pm 58.70^{c)}$ & $203.00 \pm 210.55^{c)}$ & $152.81 \pm 74.19$ & $0.035^{\mathrm{b})}$ \\
\hline LDL cholestrol & $87.53 \pm 21.22^{c)}$ & $119.60 \pm 34.31^{c)}$ & $110.52 \pm 37.56$ & $0.020^{b)}$ \\
\hline Insulin dose (IU/mL/kg) & $0.84 \pm 1.17$ & $1.16 \pm 0.39^{c)}$ & $0.86 \pm 0.32$ & $0.015^{b)}$ \\
\hline 25-OHD (ng/mL) & $14.80 \pm 5.95^{c)}$ & $8.97 \pm 2.86$ & $9.06 \pm 2.92$ & $<0.001^{\text {b) }}$ \\
\hline Vitamin D deficiency rate ${ }^{a)}$ & $16 / 20(80.0)$ & $10 / 10(100)$ & $21 / 21(100)$ & \\
\hline
\end{tabular}

Values are presented as number (\%) or mean \pm standard deviation.

DM, diabetes mellitus; ALP, alkaline phosphatase; HbA1c, glycosylated hemoglobin; LDL, low-density lipoprotein; 25-OHD, 25-hydroxy vitamin D.

${ }^{\text {a) }}$ Percentage of serum $25-\mathrm{OHD}$ level below $20 \mathrm{ng} / \mathrm{mL}$ in patients with type $1 \mathrm{DM} .{ }^{\mathrm{b}} \mathrm{P}<0.05$. ${ }^{\mathrm{c}}$ Statistical significances were tested by one way analysis of variances among groups. The same markers indicate nonsignificant difference among groups based on Duncan multiple comparison test.

Table 4. Comparision between type 1 DM patients and control groups in 25-OHD level and vitamin D deficiency according to age

\begin{tabular}{|c|c|c|c|c|}
\hline \multirow{2}{*}{ Variable } & \multicolumn{3}{|c|}{ Grade } & \multirow{2}{*}{ Total } \\
\hline & Elementary school (7-12 yr) & Middle school (13-15 yr) & High school (16-18 yr) & \\
\hline \multicolumn{5}{|l|}{ Winter season } \\
\hline \multicolumn{5}{|l|}{ Type 1 DM } \\
\hline $25-\mathrm{OHD}(\mathrm{ng} / \mathrm{mL})$ & $14.80 \pm 5.95$ & $8.97 \pm 2.86$ & $9.06 \pm 2.92$ & $11.29 \pm 5.14$ \\
\hline Deficiency rate ${ }^{a)}(\%)$ & $16 / 20(80.0)$ & $10 / 10(100)$ & $21 / 21(100)$ & $47 / 51(92.2)$ \\
\hline \multicolumn{5}{|l|}{ Control } \\
\hline $25-\mathrm{OHD}(\mathrm{ng} / \mathrm{mL})$ & $12.05 \pm 5.08$ & $9.98 \pm 3.29$ & $10.72 \pm 3.31$ & $10.98 \pm 3.97$ \\
\hline Deficiency rate ${ }^{a)}(\%)$ & 15/16 (93.8) & $12 / 12(100)$ & $21 / 21(100)$ & $48 / 49(98.0)$ \\
\hline$P$-value ${ }^{b)}$ & 0.152 & 0.458 & 0.092 & 0.732 \\
\hline \multicolumn{5}{|l|}{ Summer season } \\
\hline \multicolumn{5}{|l|}{ Type 1 DM } \\
\hline $25-\mathrm{OHD}(\mathrm{ng} / \mathrm{mL})$ & $20.28 \pm 5.09$ & $16.35 \pm 6.28$ & $15.21 \pm 5.95$ & $17.69 \pm 6.03$ \\
\hline Vitamin D Deficiency rate ${ }^{\mathrm{a})}(\%)$ & $8 / 22(36.4)$ & 10/13 (76.9) & $12 / 16(75.0)$ & $30 / 51(58.8)$ \\
\hline \multicolumn{5}{|l|}{ Control } \\
\hline 25-OHD (ng/mL) & $19.38 \pm 4.31$ & $19.43 \pm 5.28$ & $17.23 \pm 6.92$ & $18.92 \pm 5.28$ \\
\hline Vitamin D Deficiency rate ${ }^{\mathrm{a})}(\%)$ & 25/41 (61.0) & 18/27 (66.7) & 14/19 (73.7) & $57 / 87(65.5)$ \\
\hline$P$-value ${ }^{b)}$ & 0.462 & 0.113 & 0.367 & 0.210 \\
\hline
\end{tabular}

Values are presented as mean \pm standard deviation or number (\%).

DM, diabetes mellitus; 25-OHD, 25-hydroxy vitamin D.

${ }^{\text {a) }}$ Percentage of serum 25-OHD level below $20 \mathrm{ng} / \mathrm{mL}$ in patients with type $1 \mathrm{DM}$. ${ }^{\text {b) }}$ We compared about mean value of 25-OHD between type $1 \mathrm{DM}$ and control. Statistical significances were tested by independent $t$-test. 
HbA1c levels. Serum 25-OHD levels in the elementary school group were higher than in the middle and high school groups $(14.8 \pm 6.0,8.97 \pm 2.86$, and $9.06 \pm 2.92 \mathrm{ng} / \mathrm{mL}$, respectively). However, vitamin D deficiency rates were high in all groups (elementary school group, 80\%; middle and high school groups, $100 \%)$. There was no difference between the type $1 \mathrm{DM}$ group and the control group (Table 4).

\section{Clinical characteristics of children with diabetes and vitamin $\mathrm{D}$ deficiency rate in summer}

In summer, the age and sex ratio was similar between the diabetes and control groups, but BMI and serum levels of cholesterol, triglycerides, and LDL were higher in the diabetes group (Table 5). The diabetes and control groups had serum 25 OHD levels of $17.6 \pm 5.6$ and $18.9 \pm 5.3 \mathrm{ng} / \mathrm{mL}$, respectively. The absolute levels were higher in summer than in winter, but there was no difference between both groups. Vitamin D deficiency rates were relatively high, with results of $62.0 \%$ (diabetes group) and $65.5 \%$ (control group). The percentage of patients with serum 25 -OHD levels below $10 \mathrm{ng} / \mathrm{mL}$ was $8.5 \%$ and $3.4 \%$ in the diabetes and control groups, respectively. In summer, we compared and analyzed 51 children with diabetes according to school grade and age (Table 6). Similar to winter, the serum 25 -

Table 5. Clinical characteristics of patients with diabetes during summer $(n=193)$

\begin{tabular}{|c|c|c|c|c|c|}
\hline & Type 1 DM & Type 2 DM & Total & Control & $P$-value ${ }^{\text {a) }}$ \\
\hline No. of patients & $51(71.8)$ & $20(28.2)$ & $71(100)$ & 87 & \\
\hline Age (yr) & $12.73 \pm 3.60$ & $13.95 \pm 2.66$ & $13.08 \pm 3.39$ & $12.93 \pm 2.25$ & 0.755 \\
\hline M/F (male\%) & 20/31 (39.2) & $10 / 10(50.0)$ & $30 / 41(42.3)$ & $37 / 50(42.5)$ & 0.972 \\
\hline Body mass index $\left(\mathrm{kg} / \mathrm{m}^{2}\right)$ & $19.05 \pm 3.82$ & $23.78 \pm 4.52$ & $20.38 \pm 4.53$ & $18.93 \pm 3.09$ & 0.030 \\
\hline Cholesterol (mg/dL) & $183.33 \pm 45.33$ & $178.00 \pm 45.01$ & $181.83 \pm 44.98$ & $155.49 \pm 29.08$ & $<0.001$ \\
\hline Triacyglyceride (mg/dL) & $144.61 \pm 113.37$ & $152.30 \pm 76.35$ & $146.77 \pm 103.80$ & $92.54 \pm 48.13$ & $<0.001$ \\
\hline LDL cholestrol (mg/dL) & $99.98 \pm 35.60$ & $105.37 \pm 37.21$ & $101.58 \pm 35.87$ & $86.14 \pm 23.40$ & 0.037 \\
\hline 25-OHD (ng/mL) & $17.69 \pm 6.03$ & $17.28 \pm 4.29$ & $17.57 \pm 5.57$ & $18.92 \pm 5.28$ & 0.121 \\
\hline$<10$ & $5(9.8)$ & $1(5.0)$ & $6(8.5)$ & $3(3.4)$ & \\
\hline 10 to $<20$ & $25(49.0)$ & $13(65)$ & $38(53.5)$ & $54(62.1)$ & \\
\hline 20 to $<30$ & $20(39.2)$ & $6(30.3)$ & $26(36.6)$ & $28(32.2)$ & \\
\hline$\geq 30$ & $1(2.0)$ & 0 & $1(1.4)$ & $2(2.3)$ & \\
\hline
\end{tabular}

Values are presented as number (\%) or mean \pm standard deviation.

DM, diabetes mellitus; LDL; low-density lipoprotein; 25-OHD, 25-hydroxy vitamin D.

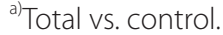

Table 6. Clinical characteristics according to age in patients with Type 1 DM during summer $(n=51)$

\begin{tabular}{|c|c|c|c|c|}
\hline \multirow{2}{*}{ Characteristic } & \multicolumn{3}{|c|}{ Grade } & \multirow{2}{*}{$P$-value } \\
\hline & Elementary school (7-12 yr) & Middle school (13-15 yr) & High school (16-18 yr) & \\
\hline No. of patients & $22(43.1)$ & $13(25.5)$ & $16(31.4)$ & \\
\hline Age (yr) & $9.24 \pm 2.14^{c)}$ & $13.72 \pm 0.98^{c)}$ & $16.74 \pm 0.37$ & $<0.001^{b)}$ \\
\hline DM duration (yr) & $3.72 \pm 2.36$ & $3.25 \pm 2.47$ & $7.25 \pm 4.61$ & $0.002^{b)}$ \\
\hline M/F (male\%) & $7 / 15$ (31.8) & $5 / 8(38.5)$ & $8 / 8(50.0)$ & 0.266 \\
\hline Body mass index $\left(\mathrm{kg} / \mathrm{m}^{2}\right)$ & $16.28 \pm 2.14^{c}$ & $20.94 \pm 3.71$ & $21.33 \pm 3.36$ & $<0.001^{b /}$ \\
\hline ALP (IU/L) & $325.91 \pm 91.85^{c)}$ & $215.69 \pm 146.23^{c)}$ & $104.56 \pm 29.40$ & $<0.001^{b}$ \\
\hline Glucose (mg/dL) & $249.52 \pm 142.26$ & $201.15 \pm 111.38$ & $224.19 \pm 121.70$ & 0.561 \\
\hline $\mathrm{HbA1c}(\%)$ & $8.59 \pm 1.33$ & $8.73 \pm 2.05$ & $9.11 \pm 1.54$ & 0.608 \\
\hline C-peptide (ng/mL) & $0.41 \pm 1.08$ & $0.58 \pm 1.65$ & $0.68 \pm 1.41$ & 0.146 \\
\hline Cholesterol (mg/dL) & $174.23 \pm 35.31$ & $190.15 \pm 63.26$ & $190.31 \pm 41.09$ & 0.467 \\
\hline Triacylglyceride (mg/dL) & $97.41 \pm 58.75^{\mathrm{c})}$ & $173.00 \pm 132.72$ & $186.44 \pm 134.48$ & $0.030^{b)}$ \\
\hline LDL cholesterol (mg/dL) & $85.94 \pm 20.59$ & $114.17 \pm 52.99$ & $105.47 \pm 28.34$ & 0.077 \\
\hline 25-OHD (ng/mL) & $20.28 \pm 5.09^{c)}$ & $16.35 \pm 6.28$ & $15.21 \pm 5.95$ & $0.022^{b)}$ \\
\hline Insulin dose (IU/ml/kg) & $0.84 \pm 1.17$ & $1.14 \pm 0.39^{c)}$ & $0.93 \pm 0.30$ & $0.022^{b)}$ \\
\hline Vitamin D deficiency rate ${ }^{a)}(\%)$ & $8 / 22(36.4)$ & 10/13(76.9) & $12 / 16(75.0)$ & \\
\hline
\end{tabular}

Values are presented as number (\%) or mean \pm standard deviation.

DM, diabetes mellitus; ALP, alkaline phosphatase; HbA1c, glycosylated hemoglobin; LDL; low-density lipoprotein; 25-OHD, 25-hydroxy vitamin D.

a) Percentage of serum 25-OHD level below $20 \mathrm{ng} / \mathrm{mL}$ in patients with type $1 \mathrm{DM}$. ${ }^{\mathrm{b})} \mathrm{P}<0.05$. ${ }^{\mathrm{c}}$ Statistical significances were tested by one way analysis of variances among groups. The same markers indicate nonsignificant difference among groups based on Duncan multiple comparison test. 
OHD levels were higher in the elementary school group than in the middle and high school groups $(20.28 \pm 5.09,16.35 \pm 6.28$, and $15.21 \pm 5.95 \mathrm{ng} / \mathrm{mL}$, respectively). Vitamin D deficiency rates were higher in the middle and high school groups than in the elementary school group $(76.9 \%, 75.0 \%$, and $36.4 \%$, respectively). There was no difference between the type $1 \mathrm{DM}$ and control groups (Table 4).

\section{Relationship with serum vitamin D levels and clinical parameter}

In children with type $1 \mathrm{DM}$, serum vitamin D levels had a negative relationship with age, BMI, ALP, cholesterol, and triglyceride levels in winter. Among the clinical parameters, age had the strongest negative correlation with serum vitamin $\mathrm{D}$ levels in winter (Table 7). However, serum vitamin D levels did not have significant relationships with insulin doses or serum glucose and $\mathrm{HbAlc}$ levels. Age had the greatest negative relationship with serum vitamin D levels in summer too. In addition, serum 25-OHD levels had a significant negative relationship with insulin doses in summer. When second-order partial correlation, controlling for age and BMI, was performed, triglyceride had a negative relationship with serum vitamin D levels in summer (Table 8).

\section{Discussion}

Vitamin D is a fat-soluble vitamin and it can be classified as a prohormone as its action mechanism is similar. Vitamin D has five forms (D1-D5), among which ergocalciferol and cholecalciferol are known to be important in humans. Vitamin $\mathrm{D}$ is abundant in animal-derived foods such as blue colored fish, egg yolks, butter, margarine, and in plant-based foods such as mushrooms. However, the majority of vitamin D needed is produced in the skin by exposure to ultraviolet $B$ (UVB) radiation rather than obtained through dietary intake ${ }^{6)}$.

Table 7. Correlation coefficients of vitamin D level with other variables in patients with type 1 DM

\begin{tabular}{|c|c|c|c|c|}
\hline \multirow{2}{*}{ Variable } & \multicolumn{2}{|c|}{ Winter } & \multicolumn{2}{|c|}{ Summer } \\
\hline & $r$ & $P$-value & $r$ & $P$-value \\
\hline Age (yr) & -0.518 & $<0.001^{\mathrm{a})}$ & -0.484 & $<0.001^{\text {a) }}$ \\
\hline Body mass index $\left(\mathrm{kg} / \mathrm{m}^{2}\right)$ & -0.510 & $<0.001^{\mathrm{a})}$ & -0.393 & $0.003^{\mathrm{a})}$ \\
\hline Glucose (mg/dL) & 0.063 & 0.668 & 0.187 & 0.179 \\
\hline ALP (IU/L) & 0.405 & $0.003^{\mathrm{a})}$ & 0.307 & $0.024^{\mathrm{a})}$ \\
\hline Cholesterol (mg/dL) & -0.376 & $0.007^{\mathrm{a})}$ & -0.216 & 0.117 \\
\hline Triacyglyceride (mg/dL) & -0.515 & $<0.001^{\mathrm{a})}$ & -0.373 & $0.005^{\mathrm{a})}$ \\
\hline LDL cholesterol (mg/dL) & -0.411 & $0.003^{\mathrm{a})}$ & -0.199 & 0.176 \\
\hline HDL cholesterol (mg/dL) & 0.082 & 0.762 & 0.080 & 0.655 \\
\hline C-peptide (ng/mL) & 0.212 & 0.135 & 0.182 & 0.188 \\
\hline $\mathrm{HbA1c}(\%)$ & -0.117 & 0.414 & -0.249 & 0.069 \\
\hline Insulin dose (IU/mL/kg) & -0.242 & 0.091 & -0.323 & $0.017^{\mathrm{a})}$ \\
\hline
\end{tabular}

DM, diabetes mellitus; ALP, alkaline phosphatase; LDL; low-density lipoprotein; HDL; low-density lipoprotein; HbA1c, glycosylated hemoglobin.

${ }^{\text {a) }}$ Pearson correlation coefficient, $P<0.05$.

Table 8. Correlation coefficients of vitamin D level with other variables controlling for age and bmi in patients with type 1 DM

\begin{tabular}{|c|c|c|c|c|}
\hline \multirow{2}{*}{ Variable } & \multicolumn{2}{|c|}{ Winter } & \multicolumn{2}{|c|}{ Summer } \\
\hline & $r$ & $P$-value & $r$ & $P$-value \\
\hline HOMA-IR & -0.064 & 0.835 & 0.066 & 0.749 \\
\hline HOMA- $\beta$ & -0.426 & 0.147 & -0.174 & 0.393 \\
\hline Glucose (mg/dL) & 0.428 & 0.144 & 0.175 & 0.393 \\
\hline ALP (IU/L) & 0.381 & 0.200 & -0.241 & 0.236 \\
\hline Cholesterol(mg/dL) & -0.316 & 0.294 & -0.327 & 0.103 \\
\hline Triacylglyceride (mg/dL) & -0.219 & 0.473 & -0.418 & $0.034^{a)}$ \\
\hline LDL cholesterol (mg/dL) & -0.393 & 0.184 & -0.199 & 0.329 \\
\hline HDL cholesterol (mg/dL) & 0.002 & 0.994 & -0.275 & 0.175 \\
\hline C-peptide (ng/mL) & 0.232 & 0.445 & 0.080 & 0.698 \\
\hline $\mathrm{HbA1c}(\%)$ & 0.324 & 0.280 & -0.337 & 0.093 \\
\hline Insulin dose (IU/mL/kg) & -0.167 & 0.256 & -0.253 & 0.212 \\
\hline
\end{tabular}

DM, diabetes mellitus; HOMA-IR, homeostatic model assessment-insulin resistance; ALP, alkaline phosphatase; LDL; low-density lipoprotein; HDL; low-density lipoprotein; HbA1c, glycosylated hemoglobin.

a) Second-order partial correlation, $P<0.05$. 
During exposure to sunlight, Vitamin $\mathrm{D}_{3}$ is produced from 7-dehydrocholesterol in the skin ${ }^{7}$.

The skin's capacity to synthesize vitamin D decreases with aging and increasing pigmentation of the skin. Living at higher altitudes and fewer outdoor activities increase the risk of vitamin $\mathrm{D}$ deficiency ${ }^{7}$. The vitamin $\mathrm{D}$ deficiency rate is higher in winter than in summer, because there is insufficient sunlight during winter to stimulate the production of vitamin $\mathrm{D}$ in the skin. Vitamin D deficiency is also caused by chronic kidney disease, hepatic failure, and drugs that increase vitamin D clearance, such as rifampin, antiepileptic drugs, glucocorticoids, and immunosuppressants ${ }^{1)}$.

Traditionally, vitamin D is known to affect calcium metabolism, bone growth, and (along with parathyroid hormone) maintenance of mineral homeostasis. Recently, various studies are being carried out to clarify the relationship between vitamin $\mathrm{D}$ and diabetes ${ }^{4,5,8)}$.

The prevalence of diabetes is increasing worldwide as well as in South Korea. Huh et al. ${ }^{9)}$ reported that the maximum insulin secretory ability of the Korean population is less than half of that in the western population. Serum insulin levels in the Korean population start to decrease at lower serum glucose levels than in the western population. As a result, the Korean population cannot tolerate even a mild insulin resistant state, and diabetes develops more easily ${ }^{10)}$. Therefore, prevention of diabetes needs more attention in Korea.

The incidence of type $1 \mathrm{DM}$ is related to regional and seasonal factors ${ }^{11-13)}$. In a study on the association between UVB radiation, vitamin D status, and incidence rates of type $1 \mathrm{DM}$ in 51 regions worldwide, an association was found between low UVB radiation and higher incidence rate of type $1 \mathrm{DM}$ in children ${ }^{14)}$. Thus, we predicted that vitamin $\mathrm{D}$ can lower the risk of type $1 \mathrm{DM}$. Another study suggested that increased intake of vitamin D lowered the incidence of type 1 DM in later life ${ }^{5)}$. Another European study identified that vitamin D supplementation in children significantly reduced the risk of type $1 \mathrm{DM}^{15)}$. Although the exact mechanism of how vitamin $\mathrm{D}$ reduces the incidence of type $1 \mathrm{DM}$ has not been identified, previous studies have suggested that vitamin D acts as an immunosuppressant, lowers proliferation of lymphocytes, production of cytokines, suppresses the release of interferon- $\gamma$ and interleukin-2 ${ }^{16,17)}$, and also inhibits the destruction of pancreatic cells ${ }^{18)}$. Through these anti-inflammatory processes, vitamin $\mathrm{D}$ can suppress the death of pancreatic $\beta$ cells and play a preventive role in type $1 \mathrm{DM}^{19,20)}$. In case of type $2 \mathrm{DM}$, high intake of vitamin $\mathrm{D}$ has been identified to lower the risk of type 2 DM through a large cohort study ${ }^{21)}$. The release of insulin is dependent on calcium metabolism ${ }^{22}$. Deficiency of vitamin D or calcium is considered to cause an imbalance of calcium in pancreatic $\beta$-cells and eventually affect the release of insulin ${ }^{4)}$.

In this study, we were able to recognize that serum vitamin D levels underwent seasonal variations in children with diabetes. We considered the possibility that outdoor activities are relatively restricted in children with diabetes as compared to healthy subjects, leading to presumably higher vitamin D deficiency rates in children with diabetes. However, there was no significant difference in vitamin D deficiency rates between both groups. Another study reports that vitamin D deficiency is very common in Korean adolescents ${ }^{23)}$.

In this study, serum vitamin D levels had negative relationships with age, BMI, and ALP and triglyceride levels in children with type $1 \mathrm{DM}$. This phenomenon seemed to be related to the duration of outdoor activities. Additionally, several studies show that weight may influence vitamin D levels ${ }^{24,25}$, as body fat acts as a reservoir for vitamin $\mathrm{D}$, reducing its bioavailability ${ }^{26)}$.

Our study has several limitations. It was a retrospective study from a single institute. Therefore, it does not represent the whole diabetic population. Confounding factors such as intake of vitamin D-rich foods and duration of outdoor activities were not considered in this study. In addition, the observation periods were relatively short.

In conclusion, a clear relationship between vitamin D deficiency and diabetes was not identified in the study. In children with diabetes, serum vitamin D levels had marked seasonal variation, but there was no difference when compared with the healthy children group. This occurred because the healthy patient group had an equally high vitamin D deficiency rate. A more in-depth study is required, and additional studies including factors such as changes in glucose levels and clinical parameters after vitamin D supplementation in children with diabetes should be considered.

\section{Conflict of interest}

No potential conflict of interest relevant to this article was reported.

\section{References}

1. Holick MF. Vitamin D deficiency. N Engl J Med 2007; 357:266-81.

2. Misra M, Pacaud D, Petryk A, Collett-Solberg PF, Kappy M; Drug and Therapeutics Committee of the Lawson Wilkins Pediatric Endocrine Society. Vitamin D deficiency in children and its management: review of current knowledge and recommendations. Pediatrics 2008;122:398-417.

3. Kim SY. The pleiomorphic actions of vitamin D and its importance for children. Ann pediatr Endocrinol Metab 2013;18:45-54.

4. Pittas AG, Lau J, Hu FB, Dawson-Hughes B. The role of vitamin $\mathrm{D}$ and calcium in type 2 diabetes. A systematic review and meta-analysis. J Clin Endocrinol Metab 2007;92:2017-29.

5. Zipitis CS, Akobeng AK. Vitamin D supplementation in early childhood and risk of type 1 diabetes: a systematic review and meta-analysis. Arch Dis Child 2008;93:512-7.

6. Holick MF. Resurrection of vitamin D deficiency and rickets. J Clin Invest 2006;116:2062-72.

7. Holick MF. Sunlight and vitamin D for bone health 
and prevention of autoimmune diseases, cancers, and cardiovascular disease. Am J Clin Nutr 2004;80(6 Suppl):1678S-1688S.

8. Rhee SY, Hwang YC, Chung HY, Woo JT. Vitamin D and diabetes in Koreans: analyses based on the Fourth Korea National Health and Nutrition Examination Survey (KNHANES), 2008-2009. Diabet Med 2012;29:1003-10.

9. Huh KB, Lee HC, Chung YS, Park SW, Park YK, Park EJ, et al. Effects of Insulin secretion on glucose and lipid metabolism in Korea. Korean J Med 1994;47:295-304

10. Korean Diabetes Association. Education guideline for diabetic patient. 2nd ed. Seoul: Gold Planning, 2006:598.

11. Webb AR, Kline L, Holick MF. Influence of season and latitude on the cutaneous synthesis of vitamin D3: exposure to winter sunlight in Boston and Edmonton will not promote vitamin D3 synthesis in human skin. J Clin Endocrinol Metab 1988;67:373-8.

12. Kimlin MG, Olds WJ, Moore MR. Location and vitamin D synthesis: is the hypothesis validated by geophysical data? J Photochem Photobiol B 2007;86:234-9.

13. Karvonen M, Jantti V, Muntoni S, Stabilini M, Stabilini L, Muntoni S, et al. Comparison of the seasonal pattern in the clinical onset of IDDM in Finland and Sardinia. Diabetes Care 1998;21:1101-9.

14. Mohr SB, Garland CF, Gorham ED, Garland FC. The association between ultraviolet $\mathrm{B}$ irradiance, vitamin $\mathrm{D}$ status and incidence rates of type 1 diabetes in 51 regions worldwide. Diabetologia 2008;51:1391-8.

15. Vitamin D supplement in early childhood and risk for Type I (insulin-dependent) diabetes mellitus. The EURODIAB Substudy 2 Study Group. Diabetologia 1999;42:51-4.

16. Reichel H, Koeffler HP, Tobler A, Norman AW. 1 alpha,25Dihydroxyvitamin D3 inhibits gamma-interferon synthesis by normal human peripheral blood lymphocytes. Proc Natl Acad Sci U S A 1987;84:3385-9.

17. Rigby WF, Denome S, Fanger MW. Regulation of lymphokine production and human $\mathrm{T}$ lymphocyte activation by 1,25-dihydroxyvitamin D3. Specific inhibition at the level of messenger RNA. J Clin Invest 1987;79:165964.

18. Riachy R, Vandewalle B, Kerr Conte J, Moerman E, Sacchetti P, Lukowiak B, et al. 1,25-dihydroxyvitamin D3 protects RINm5F and human islet cells against cytokineinduced apoptosis: implication of the antiapoptotic protein A20. Endocrinology 2002;143:4809-19.

19. Casteels K, Waer M, Bouillon R, Depovere J, Valckx D, Laureys J, et al. 1,25-Dihydroxyvitamin D3 restores sensitivity to cyclophosphamide-induced apoptosis in nonobese diabetic (NOD) mice and protects against diabetes. Clin Exp Immunol 1998;112:181-7.

20. Mathieu C, Waer M, Laureys J, Rutgeerts O, Bouillon R. Prevention of autoimmune diabetes in NOD mice by 1,25 dihydroxyvitamin D3. Diabetologia 1994;37:552-8.

21. Pittas AG, Dawson-Hughes B, Li T, Van Dam RM, Willett WC, Manson JE, et al. Vitamin D and calcium intake in relation to type 2 diabetes in women. Diabetes Care 2006;29:650-6.

22. Milner RD, Hales CN. The role of calcium and magnesium in insulin secretion from rabbit pancreas studied in vitro. Diabetologia 1967;3:47-9.

23. Shin YH, Kim KE, Lee C, Shin HJ, Kang MS, Lee HR, et al. High prevalence of vitamin D insufficiency or deficiency in young adolescents in Korea. Eur J Pediatr 2012;171:147580.

24. Bischof MG, Heinze G, Vierhapper H. Vitamin D status and its relation to age and body mass index. Horm Res 2006;66:211-5.

25. Reinehr T, de Sousa G, Alexy U, Kersting M, Andler W. Vitamin D status and parathyroid hormone in obese children before and after weight loss. Eur J Endocrinol 2007;157:225-32.

26. Wortsman J, Matsuoka LY, Chen TC, Lu Z, Holick MF Decreased bioavailability of vitamin D in obesity. Am J Clin Nutr 2000;72:690-3. 